\title{
Dynamic simulation of brake pedal force effect on heavy vehicle braking distance under wet road conditions
}

\author{
M. Zamzamzadeh ${ }^{1 *}$, A.A. Saifizul ${ }^{1,2}$, R. Ramli $^{1}$ and M.F. Soong $^{1}$ \\ ${ }^{1}$ Department of Mechanical, Faculty of Engineering, \\ University of Malaya, 50603, Kuala Lumpur, Malaysia \\ *Email: mah_zamzamzadeh@yahoo.com \\ Phone: +60 3 79674597; Fax: +60 379675317 \\ ${ }^{2}$ Center for Transportation Research (CTR), Faculty of Engineering, \\ University of Malaya, 50603, Kuala Lumpur, Malaysia
}

\begin{abstract}
Recent experiences have shown that one of the main causes of heavy vehicle crashes is the braking performance. In particular, when having to decelerate in an emergency situation, such as when an unexpected object is in the road. Thus, the capability of a vehicle to come to a safe stop is one of the most important factors in preventing more accidents. Safe braking distance is influenced by many factors, such as brake pedal force, the vehicle's loading conditions, the travel speed and the road surface conditions. The aim of this study was to analyse the effect of the driver's brake pedal force on braking distance during an emergency situation, allowed for a wide range of heavy vehicle's GVW and speed. This study is carried out by using a multi-body dynamics simulation of a Single Unit Truck based on the validated vehicle model. Braking performance was estimated in terms of braking distance on a straight road with a wet surface. The findings from the braking distance simulation suggest a non-linear relationship between brake pedal force and braking distance. Finally, it reveals that, depending on the wheel lock-up situation, braking distance increases with increasing brake pedal force, and that the braking distance on a wet road is significantly affected by both the heavy vehicle's GVW and speed.
\end{abstract}

Keywords: Braking distance; heavy vehicle; multi-body dynamics; brake pedal force; road safety.

\section{INTRODUCTION}

Road traffic accidents have been consistently increasing in Malaysia and other developing countries [1]. Problems arise when the roads are wet. The cost of accidents to the public is massive, according to the Malaysian Institute of Road Safety Research (MIROS) [2], who reported that the economic cost of heavy vehicle crashes in Malaysia is estimated to be quite high compared with that for other countries. Thus, there is a need to further understand the heavy vehicle characteristics that can provide meaningful information to minimise the number of accidents. Consequently, greater safety can be achieved. There are many factors involved in HV accidents, as reported in [3, 4]. Approximately $20 \%$ of heavy vehicle crash avoidance manoeuvres involved braking. Therefore, better knowledge of heavy vehicle braking performance could have a significant effect on the accident rate and injury. The failure of a vehicle to slow down enough and stop safely without striking other vehicles or any other object demands extra consideration. Usually 
in emergency situations, the driver applies maximum brake pedal force (PF). The braking manoeuvre can be categorised into two different modes: 1) controlled or 2) locked-up wheel braking proportional to the brake PF magnitude. To improve safety, heavy vehicles with a shorter braking distance during emergency situations have become a topic of extensive research [5]. The speed of the heavy vehicles has also been recognised as one of the essential concerns in road safety. Many studies have shown a statistical relationship between speed and crash rate [6]. First principles analysis suggests that speed may be an even more critical factor for heavy vehicle safety than for other vehicles in general. This is owing to the complicated braking systems used in heavy vehicles, with different possible failure modes and performance characteristics, including locked-wheel braking and longer braking distances than those for passenger cars [7]. Moreover, as stated by Gobbi (2014), the vehicle GVW varies considerably with different loading conditions and also shows a strong association with loss of control and the inability to stop the vehicle safely [8]. However, speed and GVW are not the only factors that lead to road accidents [9-11]; past studies indicate that the rate of road accidents increases during rainy weather because it reduces the road surface's coefficient of friction $[12,13]$. If the road is slippery, the possibility of skidding accidents is high because the coupling between the tyre and the road surface, i.e. road holding capability, is reduced [14-16].

Furthermore, it appears to be a compelling rationale to evaluate the pedal force effects on braking distance, so this study offers a detailed analysis with the aim of understanding the different risk factors that influence heavy vehicle braking distance, especially heavy vehicle GVW, speed and wet road conditions. To date, very few studies have been conducted to examine PF and there are no detailed investigations into braking distance as a function of pedal force. In this paper, braking distance was evaluated using a series of heavy vehicle emergency braking simulations. A new concept of determining braking distance for heavy vehicles incorporating brake pedal force is proposed. The results show that changes in the brake pedal force and vehicle dynamic characteristics will affect a heavy vehicle's braking performance and its ability to stop safely in emergency situations. Finally, the outcome of this study is very important for heavy vehicles without an anti-lock braking system, which are commonly used in Malaysian wet roads and highways, particularly related to over speed and overloading problems.

\section{METHODS AND MATERIALS}

Today's automotive industries and academic institutions extensively employ virtual prototyping and testing as it provides a low-cost and cross functional evaluation. In addition, considering the complexity of indoor and outdoor tests to evaluate braking performance, it encourages automotive engineers to carry out different computergenerated simulations [17]. As stated in the objectives for this study, brake pedal force is the crucial element for this simulation to estimate braking distance under different vehicle GVW and speeds as influential factors. All simulations were conducted under wet road surface conditions [18]. Figure 1 shows the study workflow. The multi-body simulation technique supports a dynamic model of an actual complicated vehicle structure[19, 20]. With the arrival of multi-body system simulation programs, such as MSC.ADAMS/Truck, it has become a more practical solution to establish computer modelling to evaluate vehicle dynamics and behaviour. The given model can describe the braking process under various heavy vehicle conditions, such as speeds and GVW [21]. This methodology has been demonstrated to be very effective for predicting braking performance. Three main steps were carried out to extract braking distance results from 
the simulations: virtual HV multi-body modelling, full HV Braking analysis, and data generation and interpretation.

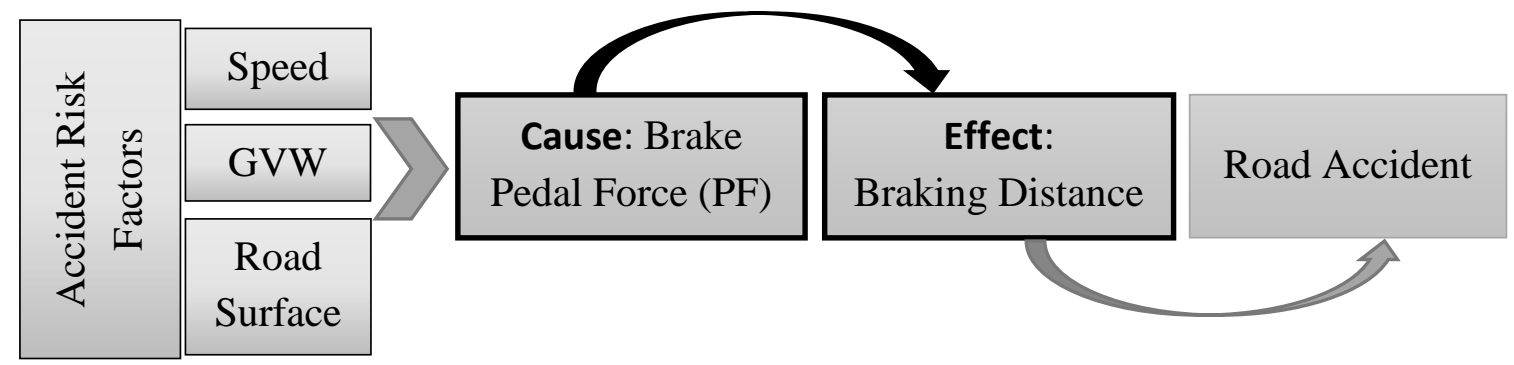

Figure 1. Study workflow.

In every simulation study, it is very important to create a model that can reproduce an actual response. In this study, a Single-Unit Truck (SUT) model with four axles and air drum brakes was developed in accordance with the trucks used on Malaysian roads. The model was reconfigured according to the existing truck's parameters, such as braking system, suspension type and wheel configuration, which are given in Table 1.

Table 1. General heavy vehicle specification.

\begin{tabular}{llc}
\hline Designation & \multicolumn{2}{c}{ Parameters } \\
\hline Dimensions $(\mathrm{m})$ & Wheelbase & 10.91 \\
\hline Weight $(\mathrm{kg})$ & Front Axle & 6840 \\
& Rear Axles & 3940 \\
& Total & 10780 \\
\hline Suspension & Front axle 3 leaf parabolic leaf springs and \\
& shock absorbers with anti-roll bar \\
& Drive axles Multilink suspension, shock absorber \\
& and air bag & \\
\hline Brakes & Air drum brakes \\
\hline Tires & Steer and drive- 315/80 R 22.5 \\
\hline
\end{tabular}

All the subsystems were created according to the vehicle components' specifications, then finally the whole set of subsystems was combined to set up the fullvehicle assembly for use in simulations. Straight line braking on a flat road was used to check the model, and the model validation was done based on published experimental results from Federal Motor Vehicle Safety Standard (FMVSS) No. 121, Air Brake Systems [22]. The results in Table 2 compare the maximum experimental braking distance for a variety of speeds permitted for unloaded test vehicles according to FMVSS No. 121 along with the simulation results. With an average $1.5 \%$ error, it shows good agreement between the simulation and experimentally obtained braking distance results, suggesting that the current heavy vehicle model can be employed to further analyse emergency braking [22]. 
Table 2. Comparison of simulation and experimental results.

\begin{tabular}{cccc}
\hline \multicolumn{4}{c}{ Simulation } \\
$\begin{array}{c}\mathrm{V} \\
(\mathrm{Km} / \mathrm{h})\end{array}$ & $\begin{array}{c}\text { Braking Distance } \\
(\mathrm{m})\end{array}$ & $\begin{array}{c}\text { Braking Distance } \\
(\mathrm{m})\end{array}$ & $\begin{array}{c}\text { Margin of Compliance } \\
(\%)\end{array}$ \\
\hline 40 & 12.65 & 12.97 & 2.45 \\
50 & 20.079 & 20.09 & 0.06 \\
60 & 29.19 & 28.94 & 0.87 \\
70 & 39.59 & 38.88 & 1.81 \\
80 & 51.3 & 50.06 & 2.48 \\
\hline
\end{tabular}

In the simulations, first the heavy vehicle starts moving on a flat and straight road profile with a wet surface to reach its desired constant speed. Then, the pedal force is applied until the vehicle reaches a complete stop. Simulation computations were performed to analyse vehicle braking distances under different conditions. The whole event was conducted under constant forward velocity starting from $40 \mathrm{~km} / \mathrm{h}$ with $10 \mathrm{~km} / \mathrm{h}$ intervals up to $80 \mathrm{~km} / \mathrm{h}$ [10]. All the simulations at the selected velocities were repeated for different GVWs. This was followed by simulations for the different brake pedal forces from 10 to $500 \mathrm{~N}$ with a $10 \mathrm{~N}$ interval. It was assumed that the road is straight and wet. In total, 2000 braking simulations were executed to examine the brake effect of pedal force on braking distance, especially for wet roads.

\section{RESULTS AND DISCUSSION}

The focus throughout this study has been the development of a straight-ahead heavy vehicle braking simulation at different speed and loading conditions on wet roads with varying pedal force applied. The braking behaviour of a heavy vehicle in emergency stops for different pedal forces was simulated. For statistical analysis, the research results were grouped according to the heavy vehicle GVW and speed. Based on the line charts shown in Figures 2 and 3, in the braking manoeuvre, the braking pedal force that was applied by the driver can be performed and result on braking distance in three different phases are expected as follows:

i) When the pedal force was increased, braking distance decreased accordingly.

ii) When the pedal force was increased, braking distance increased accordingly.

iii) When the pedal force was increased, the braking distance change was not significant.

Phase 1 occurs when the pedal force is too small to lock-up any wheel. Thus, as much as the driver increases the pedal force, the braking performance efficiently stops the heavy vehicle, thus producing a shorter braking distance. In Phase 2 the brake grips the wheel tightly to stop it from rotating; under this condition, the heavy vehicle starts to skid along the road. When the driver increases the pedal force, lock-up happens sooner or more wheels start to lock-up, thus increasing the braking distance. This phenomenon usually happens during emergency braking situations, resulting in a longer braking distance. Phase 3 indicates that dependence between pedal force and braking distance is very weak and that the pedal force has a minimum effect on the braking distance [23, 24].

From the plots for different GVWs in Figure 2, the braking distance for various heavy vehicle speeds when the GVW is constant and pedal force is increased are 
compared. Based on the plots, it can be implied that for all vehicle loading and speed conditions, the three phases of the pedal force can be observed. The safety implication of speed for heavy vehicles is that the higher the forward velocity, the longer the stopping distance. This has increases the likelihood of a rear-end collision, especially in a closefollowing situation. The result of speed alone is not enough to explain the pedal force effect on the braking distance, particularly for those involving heavy vehicles. GVW is also an important factor that needs to be considered in braking distance calculations with varying pedal force [8].
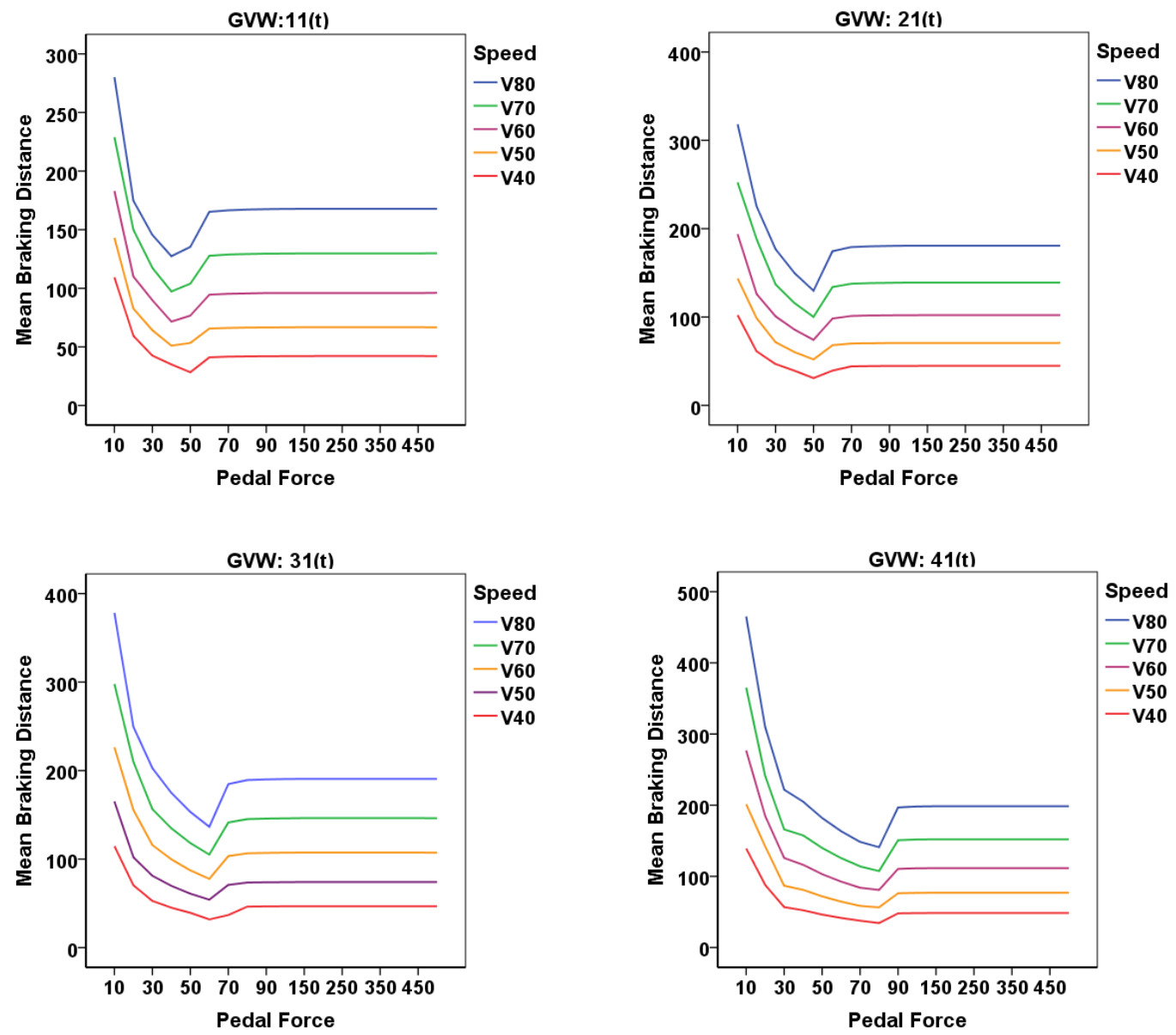

Figure 2. Simulation of the effect of brake PF on braking distance (constant GVW and different speed)

The overall simulation results from this research recommended that the variation in brake pedal force for very big forces has a minimal effect on the BD, because brake pedal forces more than $100 \mathrm{~N}$ led to skidding in an emergency braking situation, in which the brake mechanism was fully engaged and the wheel was locked $[25,26]$. For lower brake pedal forces for heavy vehicles, the brake mechanism was not fully engaged, resulting in a longer braking distance. The findings from the simulations confirmed our experimental results. The braking distances for different heavy vehicle loading conditions at a certain speed are shown in Figure 3. It can be seen that for different pedal forces, the heavy vehicle with a higher GVW has a longer braking distance. In an emergency braking situation for over loaded heavy vehicle, no matter how hard the driver applied the brake pedal, the vehicle was unable to stop with the same braking distance as those from semi- 
loaded or un-laden heavy vehicles. As overloading vehicles raises the braking distance, this could therefore increase the possibility of a rear-end collision during emergency braking in a close-following situation [27-29]. The results from all the simulations suggest that the variation in pedal force shows different effects on braking distance based on changes in speed and GVW.

The effect of GVW and speed on the pedal force properties of the heavy vehicles plays an important role in accident reconstruction. This effect has a strong influence on heavy vehicle speeds. As the speed increases, the braking distance increases accordingly. The focus of the analysis presented in this paper is the estimation of the effects of pedal force on the braking distance of heavy vehicles, which can be used for accident reconstruction purposes. It can also be seen from the above results that the larger the running speed, for the same brake pedal force, the braking distance will increase impressively. It confirms that the braking distance is affected by speed. Thus, there are scientific reasons for reducing speed to lessen the chance and the impact of a crash. Speeding or excessive speed is one of the main contributors to accidents and causes more serious accidents as vehicles require longer distances to stop.
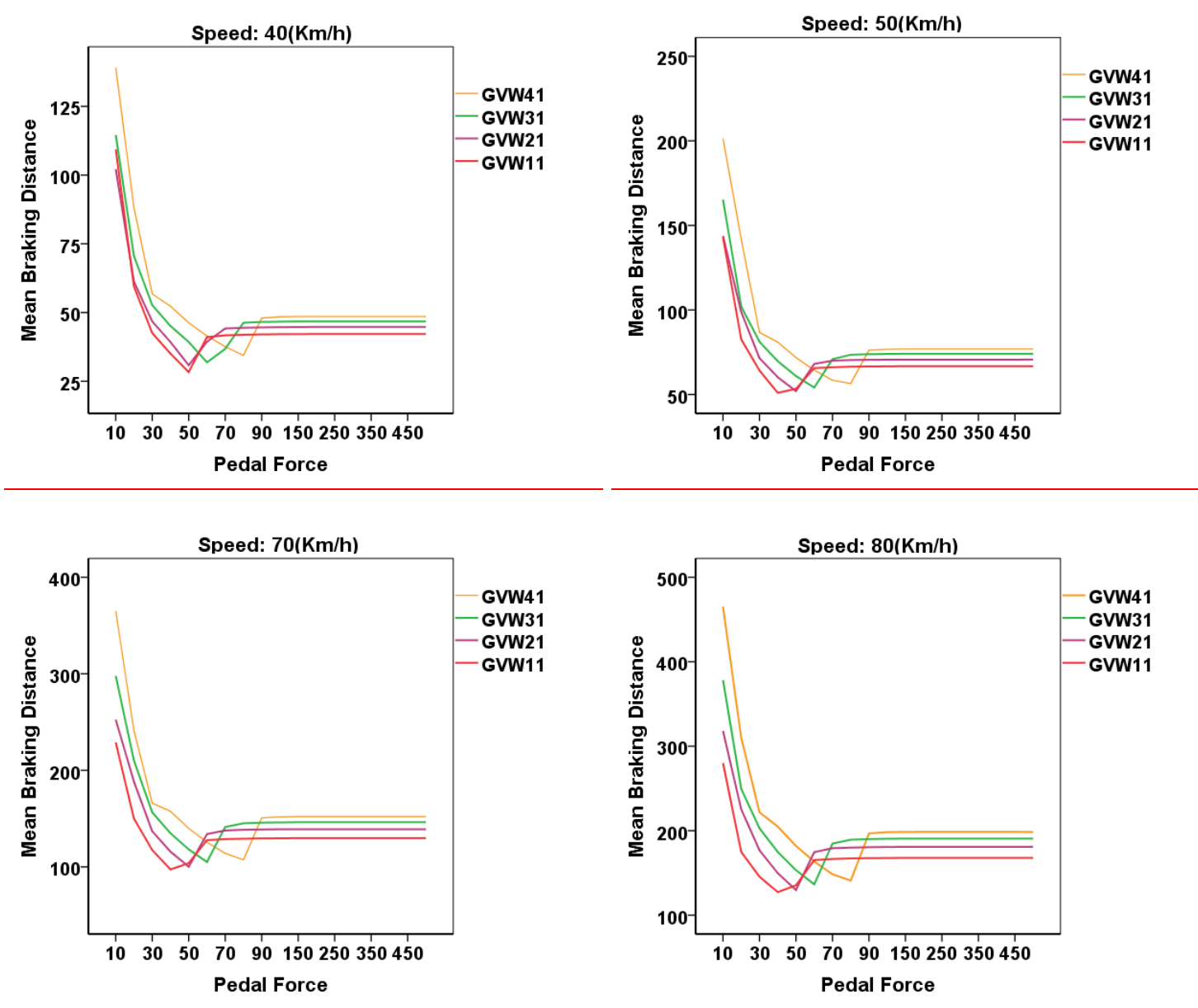

Figure 3. Simulation of the effect of brake PF on braking distance (constant speed and different GVW) 

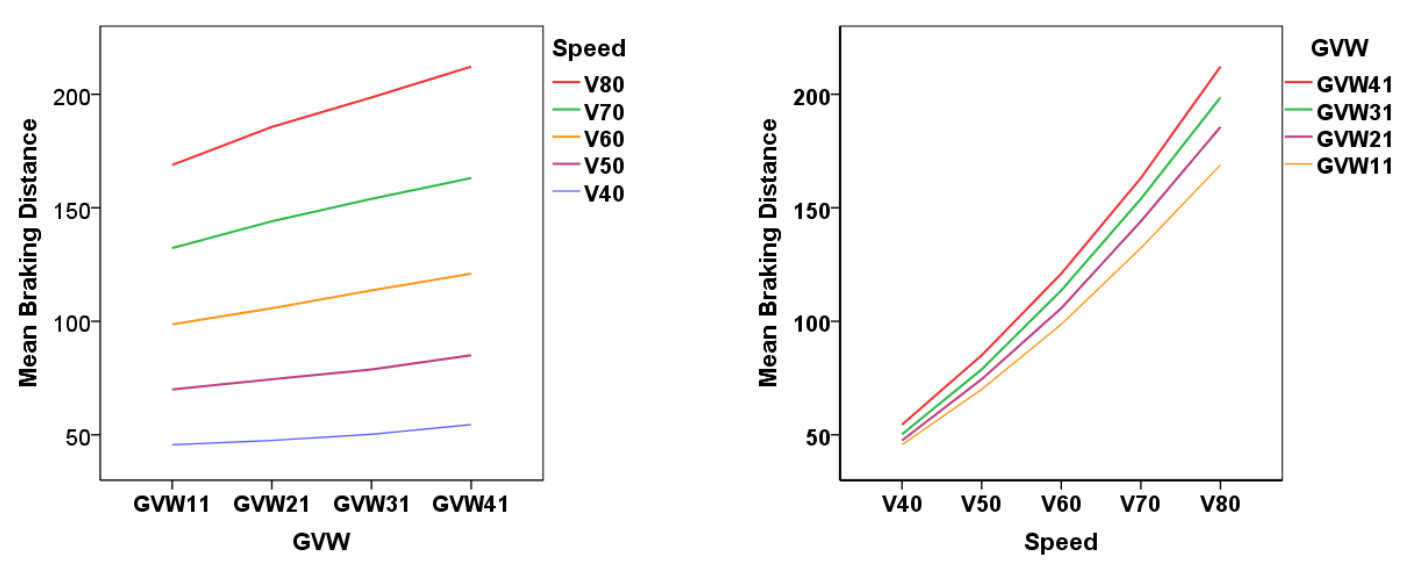

Figure 4. Simulation of the effect of GVW and speed on braking distance

Finally from Figure 4, one notable trend seems to be that braking distance steadily increases with increasing vehicle GVW and V. It also shows how large the difference between the braking distance of an empty vehicle and overloaded one can. It can clearly be seen that there is a large increase in the braking distance by increasing the initial vehicle speed, and it can be argued that for vehicles with a low speed, the GVW does not significantly affect braking distance. However, the increase in braking distance is significant when the vehicle runs at medium or high speeds.

\section{CONCLUSIONS}

In this paper, a set of simulations was done to explore the relationship between braking distance and the brake pedal force applied by the driver with various loadings and speeds on a wet road, especially in an emergency situation. The amount of brake pedal force applied during emergency braking was unknown. Therefore, this new approach could provide an insight into how the pedal force affects the braking performance of heavy vehicles. The results were examined by using a multi-body dynamics simulation of a heavy vehicle, where the braking performance was checked under various brake pedal force settings on a wet road. Additionally, the effects of speed and gross vehicle weight (GVW) were considered and examined. The results of this study suggests that braking pedal force is a very important factor, which should be considered in braking distance estimation and with regard to safety issues of heavy vehicles. Furthermore, this study suggests that vehicle speed and GVW have a significant effect on increasing braking distance, especially on wet roads. Heavy vehicle drivers should be aware of their vehicle braking performance during emergency braking, especially when their vehicle is overloaded and running at high speed.

\section{ACKNOWLEDGEMENTS}

The authors would like to thank the Ministry of Science, Technology and Innovation (MOSTI) of Malaysia for the financial support extended to this research project, 'Dynamic Rollover Warning System for Heavy Vehicle Using Weight in Motion Technology' (MOSTI Grant No. 03-01-03-SF0772). The authors would also like to express their gratitude to the Institute of Research Management and Monitoring (IPPP), University of Malaya (Grant No. UM.TNC2/IPPP/UPGP/638/PPP). 


\section{REFERENCES}

[1] Lozano R, Naghavi M, Foreman K, Lim S, Shibuya K, Aboyans V, et al. Global and regional mortality from 235 causes of death for 20 age groups in 1990 and 2010: a systematic analysis for the Global Burden of Disease Study 2010. The Lancet. 2013;380:2095-128.

[2] Fai L. Miros statistics say human error causes $80 \%$ of traffic accidents. theSundaily; 2015.

[3] Harwood DW. Review of truck characteristics as factors in roadway design: Transportation Research Board; 2003.

[4] Saifizul AA, Yamanaka H, Karim MR. Empirical analysis of gross vehicle weight and free flow speed and consideration on its relation with differential speed limit. Accident Analysis \& Prevention. 2011;43:1068-73.

[5] Jafari M, Mirzaei M, Mirzaeinejad H. Optimal nonlinear control of vehicle braking torques to generate practical stabilizing yaw moments. International Journal of Automotive and Mechanical Engineering. 2015;11:2639-53.

[6] Aarts L, Van Schagen I. Driving speed and the risk of road crashes: A review. Accident Analysis \& Prevention. 2006;38:215-24.

[7] Goudie DW, Bowler JJ, Brown CA, Heinrichs BE, Siegmund G. Tire friction during locked wheel braking. SAE Technical Paper No. 2000-01-1314; 2000.

[8] Gobbi M, Mastinu G, Previati G. The effect of mass properties on road accident reconstruction. International Journal of Crashworthiness. 2014;19:71-88.

[9] Karim MR, Abdullah AS, Yamanaka H, Abdullah AS, Ramli R. Degree of vehicle overloading and its implication on road safety in developing countries. Civil and Environmental Research. 2013;3:20-31.

[10] Sharizli A, Ramli R, Karim MR, Abdullah AS. Simulation and analysis on the effect of gross vehicle weight on braking distance of heavy vehicle. Applied Mechanics and Materials. 2014; 564:77-82.

[11] Yassenn OM, Endut IR, Hafez MA, Ishak SZ. Rutting load equivalency factors of heavy vehicles operating in the Sothern part of Malaysian Peninsula. Industrial Engineering, Management Science and Applications. 2015; 2015:429-38.

[12] Wallman C-G, Astrom H. Friction measurement methods and the correlation between road friction and traffic safety. A literature review. VTI meddelande A. 2001;911:1-47.

[13] Sledge NH, Marshek KM. Vehicle critical speed formula-values for the coefficient of friction-A review. SAE Technical Paper No. 971148; 1997.

[14] Ahammed MA. Safe, quiet and durable pavement surfaces: University of Waterloo; 2009.

[15] Andrey J, Mills B, Vandermolen J. Weather information and road safety. Institute for Catastrophic Loss Reduction, Toronto, Ontario, Canada. 2001.

[16] Bayan FP, Cornetto A, Dunn A, Wahba R, Suway J, Prokrym Y, et al. Brake characteristics for a bobtail vehicle. SAE Technical Paper; Paper No. 2013-010792; 2013.

[17] Maharun M, Baharom M, Mohd M. Ride comfort simulation of a vehicle equipped with semi-active steering system. International Journal of Automotive and Mechanical Engineering. 2015;11:2495-503.

[18] Craft R, Blower D. The large truck crash causation study. Paper presented and distributed at the November. 2004;17:2004. 
[19] Kamal M, Rahman MM, Sani MSM. Application of multibody simulation for fatigue life estimation. International Journal of Automotive and Mechanical Engineering. 2013;7:912-23.

[20] Kamal M, Rahman MM, Rahman AGA. Fatigue life evaluation of suspension knuckle using multibody simulation technique. Journal of Mechanical Engineering and Sciences. 2012;3:291-300.

[21] Ahmad F, Mazlan S, Zamzuri H, Jamaluddin H, Hudha K, Short M. Modelling and validation of the vehicle longitudinal model. International Journal of Automotive and Mechanical Engineering. 2014;10:2042-56.

[22] Garrott WR, Heitz M, Bean B. Experimental measurement of the stopping performance of a tractor-semitrailer from multiple speeds. Accident Reconstruction Journal. 2012;22:45-57.

[23] Dunn AL, Guenther DA, Radlinski R. Application of air brake performance relationships in accident reconstruction and their correlation to real vehicle performance. SAE International Journal of Commercial Vehicles. 2012;5:251-70.

[24] Gangopadhyay S, Wilson F. Analysis of the braking performance of a tractortrailer unit. Canadian Journal of Civil Engineering. 1995;22:1178-84.

[25] Xuanfeng W, Yingchun L, Guang S, Chaosheng H, Guozeng Y. A study on the asynchronous brake lock-up of a statically indeterminate tractor with an air suspension. Proceedings of the Institution of Mechanical Engineers, Part D: Journal of Automobile Engineering. 2011;226:507-16.

[26] Ong G, Fwa T. Modeling skid resistance of commercial trucks on highways. Journal of Transportation Engineering. 2009;136:510-7.

[27] Jacob B, Feypell-de La Beaumelle V. Improving truck safety: Potential of weighin-motion technology. IATSS research. 2010;34:9-15.

[28] Garrot W, Guenther D, Houk R, Lin J, Martin M. Improvement of methods for determining pre-crash parameters from skid marks. 1981.

[29] Turner D, Anne Nicholson L, Agent K. Oversize/overweight commercial vehicle safety. International Conference on Heavy Vehicles HVParis 2008: Wiley Online Library; 2008; 243-55. 